\title{
The Influence Of Predictive Factors On Survival Rate Of Burn Patients: Analysis Of 693 patients
}

Kitala D. ${ }^{1,2}$, Klama-Baryła A. 1,2, Łabuś W. ${ }^{1}$, Kraut M. ${ }^{1}$, Glik J. ${ }^{1,3}$, Nowak M. ${ }^{1}$, Kawecki M. 1,2

${ }^{1}$ Centre for Burn Treatment

2 Department of Health Sciences, Technical-Humanistic Academy

${ }^{3}$ Unit for Chronic Wound Treatment Organization, Division of Nursery, School of Health Care, Medical University of Silesia

\section{Objectives}

Traditional predictive factors, like \%TBSA or patients' age, are essential determinants of mortality risk among burn patients. The aim of this study was to evaluate additional predictive factors that influence the outcome of burned patients at the Dr. Stanislaw Sakiels' Centre for Burn Treatment in Siemianowice Śląskie, Poland.

\section{Methods}

All burned patients admitted between 01.01-01.06.2015 were included to analysis. Five models of Cox proportional hazard risk were created. A model consisting of all parameters was chosen.

\section{Results}

It was shown, that sex does not influence patients' survival, however, one year increase of age results in 3,2\% increase risk of death. An even more significant impact on surviving rate of patients is linked with burn area - risk of death increase 1,47 times for each $20 \%$ of burn surface. Unsuccessful outcome increased 0,5 times with every consecutive surgery. Patients who underwent limb amputation are at risk of death 1,8 times higher than patients with no amputation. Patients, who due their general health condition had to be admitted to the ICU, were at 9,3 times higher risk of death compared to patients hospitalized in surgery wards. Blood transfusion procedures did not influence patients' surviving rate. Rehabilitation and hyperbaric oxygenation as adjuvant therapies did not impact the risk of death.

\begin{tabular}{|l|c|}
\hline Burn TYPE & Mean \pm SD/cardinality \\
Thermical $-97 \%(\mathrm{n}=668)$ \\
Chemical $-3 \%(\mathrm{n}=24)$
\end{tabular}

-It was shown, that sex does not influence patients' survival

-One year increase of age results in 3,2\% (Cl 1,1-5,4\%; $p=0,002)$ increase risk of death of burn patients.

-An even more significant impact on surviving rate of patients is linked with burn area - risk of death increase 1,47 times for each $20 \%$ of burn surface (HR Cl 1,26-1,71; $p<0,001)$.

-Chance of survival of 3 weeks for burns with more than $80 \%$ of body surface is slightly more than $10 \%$.

-Type of burn isn't a predictive factor for death.
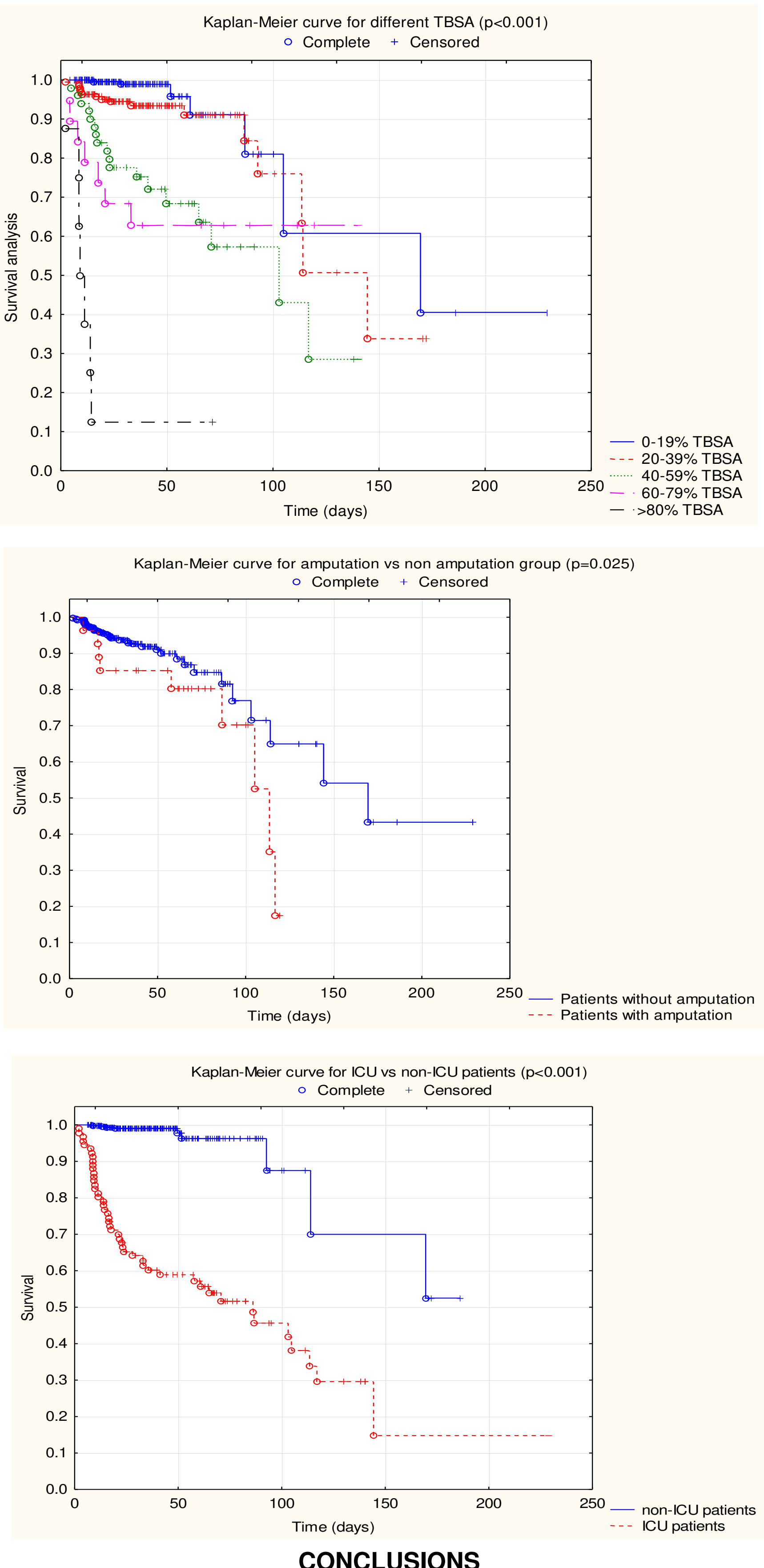

-Despite the fact that age and burn surface are unchanged factors for outcome, created models show that estimation of survival rates based on those two parameters is considered insufficient.

- Hospitalisation lenght probably is not a predictive factor for mortality, rather a consequence of other factors affecting the patient's general condition, so it's not good indicatior for performed procedures. -ICU patients with burns exceeding $80 \%$ and patients who underwent limb amputation are at particular risk. - More attention should be paid to the problem of burn wound conversion, which can lead to the need of limb amputation in the future, airways burns, hipoalbuminemia, blood infections. -Also parameters related to patients habits should be taken into consideration: alkoholism, obesity, diabetes.

- Similar analyses should be a standard procedure of every burn center. It will improve the quality of treatment and will have a positive impact on the economical aspects of burn patient treatment. 